Dokuz Eylül Üniversitesi-Mühendislik Fakültesi

Fen ve Mühendislik Dergisi

Cilt 20, Sayı 60, Eylül, 2018
Dokuz Eylul University-Faculty of Engineering Journal of Science and Engineering Volume 20, Issue 60, September, 2018

\title{
İnce Bir Çubuğun Belirsiz Doğal Frekanslarının Çokterimli Kaos Açılımı ile Matematiksel Olarak Modellenmesi
}

\author{
Murat KARA $^{* 1}$, Abdullah SEÇGINN ${ }^{2}$ \\ Dokuz Eylül Üniversitesi, Mühendislik Fakültesi, Makine Mühendisliği Bölümü, 35397, İzmir \\ 1(ORCID: 0000-0001-5798-9014) \\ 2(ORCID: 0000-0002-1896-7629)
}

(Alınıș / Received: 06.02.2018, Kabul / Accepted: 18.04.2018, Online Yayınlanma / Published Online: 15.09.2018)

Anahtar Kelimeler Özet: Belirsizlik genellikle dinamik cevaplardaki kontrol Çokterimli Kaos edilemeyen değişkenlikler olarak tanımlanır. Bu çalışma, belirsiz açlımı, Belirsiz ince çubuk, Ayrık Tekil Konvolüsyonu, Doğal frekans elastisite modülü ve özgül hacme sahip ince bir çubuğun belirsiz doğal frekanslarının matematiksel olarak modellenmesini içerir. Belirsiz değişkenlerin ötelenmiş Normal dağılıma sahip olduğu kabul edilmiştir. Belirsiz değişkenler ve bu değişkenlere karşılık gelen belirsiz doğal frekanslar çok terimli kaos (ÇKA) ile modellenmiştir. Çokterimli tipi olarak Hermite çokterimlisi seçilmiștir. Ayrık tekil konvolüsyonu (ATK) diferansiyel denklem çözücü olarak kullanılmış ve ATK'nın doğal frekansların ÇKA katsayılarını belirlemekte oldukça avantajlı olduğu görülmüştür. Çubuğun ilk otuz doğal frekansı göz önüne alınarak her bir doğal frekans için farklı ÇKA katsayıları elde edilmiştir. Doğrulama çalışması için Monte Carlo simülasyonu gerçekleştirilmiştir. Sonuçlar, ATK ile ÇKA uygulamasının Monte Carlo simülasyonuna oldukça güçlü bir alternatif olduğunu göstermektedir.

\section{Mathematical Modeling of Uncertain Natural Frequencies of a Thin Beam via Polynomial Chaos Expansion}

\begin{tabular}{|c|c|}
\hline $\begin{array}{l}\text { Keywords } \\
\text { Polynomial Chaos } \\
\text { Expansion, } \\
\text { Uncertain thin } \\
\text { beam, } \\
\text { Discrete Singular } \\
\text { Convolution, } \\
\text { Natural frequency }\end{array}$ & $\begin{array}{l}\text { Abstract: Uncertainty is generally defined as uncontrollable } \\
\text { variability in the dynamic responses. This study introduces } \\
\text { mathematical modeling of uncertain natural frequencies of a thin } \\
\text { beam having uncertain elasticity modulus and specific volume. } \\
\text { The uncertain variables are assumed to have shifted normal } \\
\text { distribution. The uncertain variables and the uncertain natural } \\
\text { frequencies corresponding to the uncertain variables are modeled } \\
\text { via polynomial chaos expansion (PCE). Hermitian polynomials are } \\
\text { selected as polynomial type. Discrete singular convolution method } \\
\text { (DSC) is utilized to solve differential equation solver and it is seen } \\
\text { that DSC presents a unique advantage in determining PCE } \\
\text { coefficients of natural frequencies. First thirty natural frequencies } \\
\text { of the beam are considered and different PCE coefficients are } \\
\text { obtained for each natural frequency. Monte Carlo simulation is } \\
\text { performed for the validation. Results show that PCE application } \\
\text { via DSC is a powerful alternative to Monte Carlo simulation. }\end{array}$ \\
\hline
\end{tabular}

*Sorumlu yazar: kara.murat@deu.edu.tr 


\section{Giriş}

Bir ürünün tasarım sürecinde yapılan vibro-akustik analizlerde belirsizlik adı verilen olgunun göz önüne alınması gereklidir. Belirsizlik, genellikle malzemenin iç yapı farklılıkları, sönüm ve geometrideki farklılıklar, ilk ve sınır şartlarındaki oynaklıklar gibi kontrol edilemeyen değişiklikler sonucu aynı ürünün farklı örneklemlerinin farklı vibro-akustik özellikler göstermesi olarak tanımlanır. Güvenilir analizler için bu belirsizlikler üretimin her aşamasında hesaba katılmalıdır. Bu bağlamda, dinamik sistemlerin belirsizliği uygun bir istatistiksel yaklașım ile modellenmelidir.

Literatürde belirsizliklerin hesaplanması için birçok çalışma bulunmaktadır. Elishakoff ve ark. [1] belirsizlik analizlerinde olasılıksal ve olasılıksal olmayan yöntemlerin olduğunu belirtmişlerdir ve belirsizliğe sahip bir kafes sistemi problemini olasıllksal olmayan en kötüleștirme (antioptimizasyon) yöntemi ile çözmüşlerdir. $\mathrm{Bu}$ yöntemde yalnızca belirsiz parametrelerin sınırlarının bilinmesi durumunda yük kombinasyonlarına göre kafes sistemini oluşturan elemanların kesit alanlarını belirlemişlerdir. Aralık analizi [2] ve bulanık analiz [3,4] diğer olasılıksal olmayan yöntemlerden bazılarıdır.

Olasılıksal yöntemlerde ise, belirsiz parametrelerin dağılım tipi ve istatistiksel özelliklerinin bilinmesi durumda sistem cevabı olasılık teorisi kullanılarak belirlenir. Literatürde birçok olasılıksal yöntem olmasına rağmen Monte Carlo simülasyonu [5,6] tabanlı sayısal analizler en çok kullanılan tekniklerden biridir. Fakat bu yöntemde hesaplama sürelerinin uzunluğu ve hafiza kullanımının artması nedeniyle alternatif olasılıksal yöntemler araştırılmaktadır. Başka bir olasılıksal yöntem olan İstatitistiksel Enerji Analizi [7] ise oldukça kısa sürelerde hesaplamalar yapabilmektedir. Fakat bu teknik ile birçok kabul ve kısıtlamalar nedeni ile yalnızca yüksek frekanslarda titreșen yapıların analizleri doğru olarak yapılmaktadır.

Çokterimli kaos açılımı (ÇKA) yöntemi [8-10] belirsiz dinamik sistemlerin analizinde kullanılabilen bir başka olasılıksal yöntemdir. $\mathrm{Bu}$ yöntemde, belirsiz değișkenlerin dağılımları uygun bir sabit katsayılı çokterimli ile modellenir. Bu nedenle bu yöntem, diğer belirsizlik analizi yapabilen tekniklerin yapamadığı belirsizliğin matematiksel modelini ortaya koyabilmektedir. Ayrıca yöntemin, sonlu elemanlar [8] ve sonlu farklar analizi [9] gibi deterministik teknikler ile birlikte kullanılabilmesi bir diğer avantajıdır. Fakat bu yöntemde uygun olmayan dağılım-çok terimli ikilisi seçilmesi durumunda yüksek dereceli terimlerin sıfıra yakınsamaması nedeniyle hesaplama süreleri oldukça uzamaktadır.

Bu çalışmada, belirsiz elastisite ve özgül hacme sahip ince çubuğun belirsiz doğal frekansları ÇKA yöntemi ile belirlenmiştir. Belirsiz değişkenlerin ötelenmiş normal dağılıma sahip olduğu kabul edilmiştir ve bu değişkenler Hermite çokterimlileri ile ifade edilmiștir. Diferansiyel denklemin çözümünde ayrık tekil konvolüsyonu (ATK) [11-17]. Böylelikle bu çalışma ile ilk defa ÇKA katsayıları, ATK kullanılarak belirlenmiștir. Elde edilen sonuçlar, Monte Carlo simülasyonu ile karşılaştırılmıştır. Sonuç olarak ATK ile yapının karakteristik matrisin bir defa elde edilmesi ile belirsiz doğal frekanslarının CKA yöntemi kullanılarak başarılı bir şekilde elde edildiği görülmüștür. 


\section{Matematiksel Bağıntılar}

\subsection{Belirsiz bir ince çubuğunun kısmi diferansiyel denklemi}

İnce bir çubuğun harmonik serbest eğilme titreșimi [18],

$$
\operatorname{Er} \frac{I_{z}}{A} W^{(I V)}(x)-\omega_{n}^{2} W(x)=0
$$

ile ifade edilir. Burada, $r$ çubuğun özgül hacmi (yoğunluğun tersi), $E$ elastisite modülü, $A$ çubuğun kesit alanı, $I_{z} \mathrm{z}$ ekseni etrafındaki alan atalet momenti, $W$ çubuğun titreșim genliği, üst indis (IV) titreşim genliğinin uzam değişkeni olan $x^{\prime}$ e göre 4. dereceden türevi ve $\omega_{n}$ ise çubuğun doğal frekansıdır. Basit mesnetli bir çubuk için doğal frekanslar analitik olarak [18],

$$
\omega_{n}=(k \pi)^{2} \sqrt{\frac{E r I_{z}}{A l^{4}}}, \quad k=1,2,3 \ldots
$$

ile ifade edilir. Burada, $l$ çubuğun uzunluğudur. $\mathrm{Bu}$ çalışmada, elastisite modülü ve özgül hacmin birbirinden bağımsız olarak belirsiz değişken olduğu kabul edilmiștir. Bu durumda, Denklem (1) şu şekilde yazılabilir:

$$
\begin{aligned}
E\left(\xi_{1}\right) r\left(\xi_{2}\right) \frac{I_{z}}{A} W^{(I V)}\left(x, \xi_{1}, \xi_{2}\right) \\
-\omega_{n}^{2}\left(\xi_{1}, \xi_{2}\right) W\left(x, \xi_{1}, \xi_{2}\right)=0
\end{aligned}
$$

Burada, $\xi_{1}$ ve $\xi_{2}$ elastisite modülü ve özgül hacmi etkileyen belirsiz parametrelerdir.

\subsection{Belirsiz ince çubuk için Ayrık Tekil Konvolüsyonu (ATK)}

ATK algoritmasına göre, bir fonksiyon ve onun $n$. dereceden türevi şu şekilde ifade edilebilir [11]:

$$
W_{i}^{(n)} \approx \sum_{k=-M}^{M} \delta_{\alpha, \Delta}^{(n)}\left(x_{i}-x_{k}\right) W_{i+k}
$$

Burada, $M$ bant genişliği, $x_{k}$ düzgün dağıtılmış ayrıklaştırılmış noktalar, $\delta_{\alpha, \Delta}^{(n)}\left(x_{i}-x_{k}\right)$ ise Dirichlet tipli ATK çekirdeğidir. Literatürde birçok ATK çekirdeği bulunmasına rağmen, düzenlenmiş Shannon delta çekirdeği bu çalışmada kullanılmıştır [19]:

$$
\begin{gathered}
\delta_{\alpha, \beta}^{(n)}\left(x_{i}-x_{k}\right)=\left(\frac{d}{d x}\right)^{n}\left(\frac{\sin \left(\alpha\left(x-x_{k}\right)\right)}{\alpha\left(x-x_{k}\right)},\right. \\
\left.\cdot \exp \left(-\left(x-x_{k}\right)^{2} / 2 \beta^{2}\right)\right|_{x=x_{i}}
\end{gathered}
$$

Burada, $\quad \alpha=\pi / \Delta \quad$ Nyquist frekansı, $\Delta=L /(N-1)$ ayrıklaştırılmış noktalar arasındaki mesafe, $N$ ayrık nokta sayısı ve $\beta=(N / 10+1) \Delta$ 'dır. Sadeleştirme amacıyla, Denklem (4) şu şekilde ifade edilebilir:

$$
W_{i}^{(n)} \approx \sum_{k=-M}^{M} C_{k}^{(n)} W_{i+k}
$$

Denklem (6)'nın Denklem (3)'de yerine koyulması ile her bir ayrık nokta için şu denklem elde edilir:

$$
\begin{array}{r}
E\left(\xi_{1}\right) r\left(\xi_{2}\right) \frac{I_{z}}{A} \sum_{k=-M}^{M} C_{k}^{(4)} W\left(x, \xi_{1}, \xi_{2}\right) \\
-\omega_{n}^{2}\left(\xi_{1}, \xi_{2}\right) W\left(x, \xi_{1}, \xi_{2}\right)=0
\end{array}
$$

Denklem (7)’ye sınır koşulu uygulanmasının ardından ince çubuğun doğal frekansları, şu denklemin çözülmesi ile elde edilir:

$$
\left|E\left(\xi_{1}\right) r\left(\xi_{2}\right) \frac{I_{z}}{A} D^{(4)}-\omega_{n}^{2}\left(\xi_{1}, \xi_{2}\right) I\right|=0
$$

Burada, $D^{(4)} \quad N x N$ boyutlu dördüncü dereceden ATK karakteristik matrisi, I 
ise birim matristir. ATK ile sınır koşulu uygulamaları için literatürdeki $[16,17,20,21]$ çalışmalar incelenebilir.

\section{3. Çokterimli Kaos Açılımı (ÇKA)}

ÇKA'na göre, belirsiz bir değişken $(Y)$ birbirine dik çokterimliler cinsinden şu şekilde ifade edilebilir [8-10]:

$$
\begin{aligned}
Y= & y_{0} \psi_{0}+\sum_{i_{1}=1}^{\infty} y_{i_{1}} \psi_{1}\left(\xi_{i_{1}}\right) \\
& +\sum_{i_{1}=1}^{\infty} \sum_{i_{2}=1}^{i_{1}} y_{i_{1} i_{2}} \psi_{2}\left(\xi_{i_{1}}, \xi_{i_{2}}\right) \\
& +\sum_{i_{1}=1}^{\infty} \sum_{i_{2}=1}^{i_{1}} \sum_{i_{3}=1}^{i_{2}} y_{i_{1} i_{2} i_{3}} \psi_{3}\left(\xi_{i_{1}}, \xi_{i_{2}}, \xi_{i_{3}}\right)+\ldots
\end{aligned}
$$

veya basitçe

$$
Y=\sum_{i=0}^{\infty} y_{i} \psi_{i}(\xi)
$$

Burada, $\quad \xi=\left[\xi_{1}, \xi_{2}, \ldots, \xi_{i_{n}}\right], \quad$ belirsiz değişkeni $(Y)$ etkileyen belirsiz parametrelerden oluşan vektördür. $y_{i}$, çok terimlilerin deterministik katsayıları ve $\psi_{i}($.$) ise birbirine dik çok$ terimlilerdir. Çok terimliler birbirine dik olduğundan,

$$
\left\langle\psi_{i} \cdot \psi_{j}\right\rangle=\left\{\begin{array}{ll}
0, & i \neq j \text { ise } \\
\left\langle\psi_{i}^{2}\right\rangle, & i=j \text { ise }
\end{array} .\right.
$$

Burada, \langle\rangle çok terimlilerin ortalamasını gösterir. Denklem (10)'da görüldüğü ÇKA sonsuz terimlidir. Sayısal çalışmalarda, seriyi sonlu bir değerde $\left(N_{P C}\right)$ sonlandırmak anlamlı olacaktır:

$$
N_{P C}=\frac{(m+p) !}{m ! p !} .
$$

Burada, $p$ çok terimlinin derecesi, $m$ ise belirsiz parametrenin boyutudur, örneğin $m=2$ ise $\xi=\left[\xi_{1}, \xi_{2}\right]$.

ÇKA'nda bilinmeyen deterministik katsayılar, $y_{i}$, Galerkin iz düşümü (ilgilenilen denklemi temel (basis) fonksiyon ile çarpma olarak tanımlanabilir) ile belirlenir [8]:

$$
y_{i}=\frac{1}{\left\langle\psi_{i}^{2}\right\rangle} \int_{\Omega}\left\langle Y, \psi_{k}(\xi)\right\rangle d \mu(\xi),
$$

burada, $d \mu(\xi)$ rastgele değişken uzayın $(\Omega)$ olasılığıdır ve $k=0,1,2,3, \ldots$ Eğer belirsiz değişken çok boyutlu ise, Denklem (13) çok katlı integral ile ifade edilir:

$$
y_{i}=\frac{1}{\left\langle\psi_{i}^{2}\right\rangle_{\Omega_{1}}} \int_{\Omega_{m}} \ldots \int_{\Omega_{m}}\left\langle Y, \psi_{k}(\xi)\right\rangle d \mu_{m}\left(\xi_{m}\right) \ldots d \mu_{1}\left(\xi_{1}\right)
$$

ÇKA'nda Hermite çok terimlileri fonksiyon seti, $\psi_{i}$, olarak kullanılabilir:

$$
H_{i}(\xi)=(-1)^{i} e^{\frac{1}{2^{T} \xi^{T} \xi}} \frac{\partial^{i}}{\partial \xi_{i_{1}} \partial \xi_{i_{2}} \ldots \partial \xi_{i_{n}}} e^{-\frac{1}{2} \xi^{T} \xi}
$$

ÇKA ile belirsizlik analizlerinde, belirsiz parametrenin her bir dağılım tipine göre en uygun çok terimli temeli vardır, örneğin; Normal dağılım için Hermite çok terimlisi, Gamma dağılımı için Laguerre çok terimlisi, Beta dağılımı için Jacobi çok terimlisi, düzgün (tek biçimli) dağılım için Legendre çok terimlisi [10]. Burada verilen örneklerde verilen çok terimli tipinin ağırlı fonksiyonları dağılımın matematiksel formu ile benzerdir. Eğer bir belirsiz değişken yukarıda belirtilen dağllım tipine göre en uygun çok terimli ile ifade edilirse bu durum optimum gösterim olarak isimlendirilir ve bu durumda belirsiz değişken oldukça az sayıda çok terimli katsayısı ile ifade edilebilir $\left(N_{P C}=1\right)$. Optimum ÇKA'nda, 
[a,b] aralığında belirsiz parametre $\xi$, $[c, t]$ aralı̆̆ındaki belirsiz değişkeni ifade etmekte kullanılırsa, belirsiz parametre şu şekilde ötelenmelidir:

$$
\int_{c}^{Y} \rho_{1}(u) d \tau=\int_{a}^{\xi} \rho_{2}(u) d \tau
$$

Burada, $\rho$ olasılık dağılım fonksiyonunu gösterir. Denklem (16) düzenlendiğinde,

$$
Y=f(\xi),
$$

elde edilir. Bunun yanında, herhangi bir dağlım herhangi bir çokterimli ile ifade edilebilir. Bu durumda, açılım, optimum olmayan CKA olarak isimlendirilir ve bu durumda belirsiz değişken çok sayıda terim ile ifade edilir $\left(N_{P C}>1\right)$ ve hesaplama süreleri oldukça artar ve ÇKA katsayıları sıfıra yakınsamaz.

\section{Sayısal Çalışmalar}

Bu bölümde, ince çubuğun belirsiz doğal frekansları CKA ile matematiksel olarak ifade edilmiştir. ATK kısmi diferansiyel denklem çözücü olarak kullanılmıştır. Bu bağlamda, ilk olarak ATK yönteminin doğrulaması Bölüm 3.1'de yapılmıștır. Daha sonra, belirsiz değişkenler, elastisite modülü ve özgül hacim, Bölüm 3.2'de ayrıca belirsiz doğal frekanslar Bölüm 3.3'de ÇKA ile modellenmiștir. İncelenen çubuğun kesit alanı $A=10 \mathrm{~cm} \mathrm{x}$ $10 \mathrm{~cm}$, uzunluğu $10 \mathrm{~m}$, ortalama özgül hacmi, $r=3.7176 \times 10^{-4} \mathrm{~m}^{3} / \mathrm{kg}$ ve ortalama elastisite modülü $68 \mathrm{GPa}$ 'dır.

\subsection{ATK yönteminin doğrulaması}

Bu bölümde, ATK yönteminin doğruluğu doğal frekansların hesaplanarak analitik sonuçlar ile karșılaștırılması ile gösterilmiștir. Bu bağlamda, ATK ile basit mesnetli bir çubuğun doğal frekansları farklı ayrıklama sayıları (N) için elde edilmiştir. Şekil 1'de farklı ayrıklama sayıları için elde edilen doğal frekansların

\%error $=\left(\omega_{D S C}-\omega_{a n}\right) / \omega_{a n} \times 100 \quad$ ile hesaplanan analitik sonuçlardan sapma miktarı gösterilmiştir.

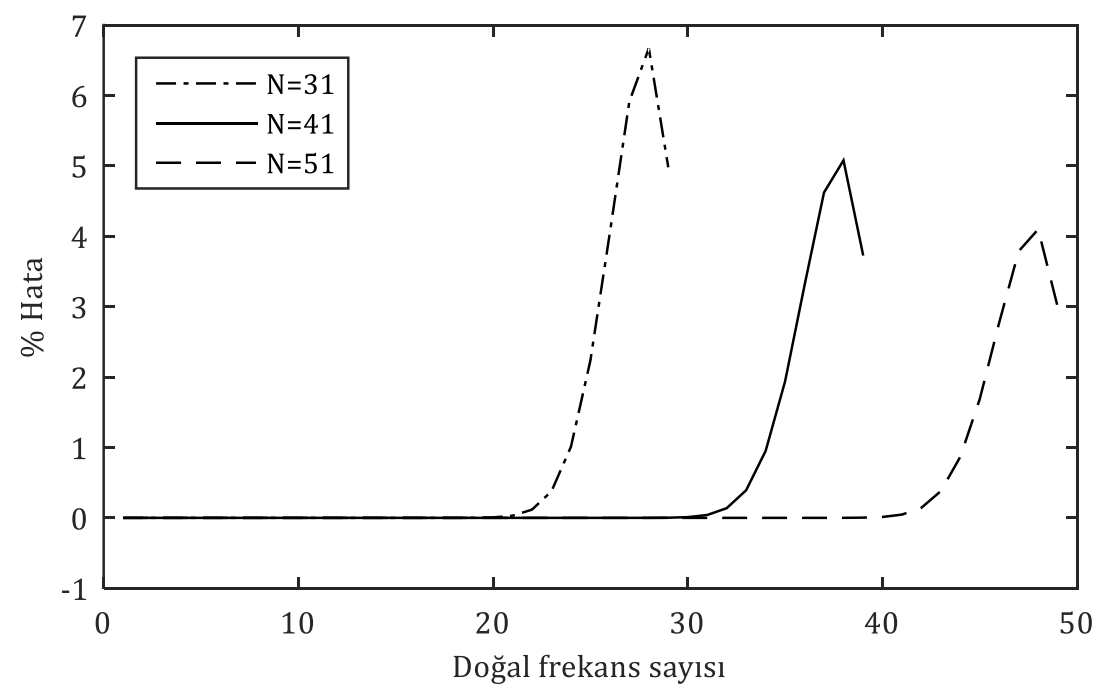

Şekil 1. Farklı ayrıklama sayılarına göre doğal frekansların \% hata eğrileri

Şekil 1'de görüldüğü gibi ayrıklama frekanslar oldukça hassas olarak elde sayısından bağımsız olarak ilk doğal edilmiștir. Fakat analizlerde ilk 30 doğal 
frekans $(10000 \mathrm{~Hz})$ göz önüne alınmıştır. Bu nedenle Şekil 1'de görülen hata değeri $\% 1$ 'den az olduğu için bundan sonraki analizlerde ayrıklama sayısı $N=41$ olarak seçilmiştir.

\subsection{Elastisite modülü ve özgül hacmin optimum çok terimli kaos açılımı}

İnce çubuğun elastisite modülü ve özgül hacmi belirsiz olarak seçilerek Normal dağılıma sahip olduğu kabul edilmiştir. Bu belirsiz değișkenler sırasıyla,

$$
\begin{aligned}
& \qquad\left[\mu_{E}, \sigma_{E}\right]=[68 ; 0,05 \times 68] \times 10^{9} \\
& \text { ve } \\
& {\left[\mu_{r}, \sigma_{r}\right]=[3,7176 ; 0,05 \times 3,7176] \times 10^{-4}}
\end{aligned}
$$

özelliklerine sahip olduğu kabul edilmiștir. Burada, $\mu$ ortalama değeri, $\sigma$ standart sapmayı göstermektedir. Elastisite modülü ve özgül hacim sirasiyla $\xi_{1}$ ve $\xi_{2}$ belirsiz parametreleri kullanılarak Hermite çok terimlisi ile ifade edilecektir. Belirsiz parametreler birbirine eş istatistiksel özelliklere ve $\left[\mu_{\xi}, \sigma_{\xi}\right]=[0,1]$ ile ifade edilen Normal dağılıma sahip olduğu kabul edilmiştir. Elastisite modülü ve özgül hacim Bölüm 2.3'de bahsedildiği gibi ötelenmiş ve sırasıyla aşağıdaki verilen çok terimliler ile ifade edilmiştir:

$$
E=\sum_{i=0}^{1} E_{i} H_{i}\left(\xi_{1}\right)=68 \times 10^{9}+34 \times 10^{8} \xi_{1}
$$

ve benzer şekilde,

$$
\begin{aligned}
r=\sum_{v=0}^{1} r_{v} H_{v}\left(\xi_{2}\right) & =3,7176 \times 10^{-4} \\
+ & 0,18588 \times 10^{-4} \xi_{2}
\end{aligned}
$$

Görüldüğü gibi Normal dağllımlı bir belirsiz parametre uygun çok terimli tipi olan Hermite çok terimlileri ile modellendiğinde yalnızca birinci dereceden çok terimli ile ifade edilebilmektedir.

\subsection{Belirsiz doğal frekansların ÇKA ile belirlenmesi}

Çubuğun doğal frekansları da elastisite modülü ve özgül hacim gibi ÇKA ile bir çok terimli gibi modellenebilir. Doğal frekansların karesi, $\omega_{n}^{2}$, (çubuğun öz değerleri, $\Lambda_{n}$ ) ÇKA ile şu şekilde ifade edilir:

$$
\begin{aligned}
\Lambda_{n} & =\sum_{j=0}^{N_{\lambda}} \lambda_{j} H_{j}\left(\xi_{1} \otimes \xi_{2}\right)=\sum_{j=0}^{N_{\lambda}} \omega_{n, j}^{2} H_{j}\left(\xi_{1} \otimes \xi_{2}\right) \\
& =\omega_{n, 0}^{2} 1+\omega_{n, 1}^{2} \xi_{1}+\omega_{n, 2}^{2} \xi_{2}+\omega_{n, 3}^{2} \xi_{1} \xi_{2}
\end{aligned}
$$

Burada; $\quad H_{j}\left(\xi_{1} \otimes \xi_{2}\right)=H_{i}\left(\xi_{1}\right) \otimes H_{v}\left(\xi_{2}\right)$; $\otimes$, tensör çarpımı ve $\omega_{n, j}^{2}$, doğal frekansın $j$. ÇKA katsayısının karesini göstermektedir. Denklem (20) ve (21) ikișer terime sahip olduğundan doğal frekansın çokterimli kaos açılımı, 4 (2x2) terimden oluşacaktır dolayısıyla Denklem (22)'de gösterilen seri açllımı sıfırdan başladığından $N_{\lambda}=3$ olacaktır. Yukarıda verilen Denklem belirsiz doğal frekansların matematiksel ifadesi olarak tanımlanır ve problem bu Denklemde yer alan $\omega_{n, j}^{2}$ katsayılarının elde edilmesidir. Bu katsayllar, Denklem (20), (21) ve (22) Denklem (8)'de yerine yazıldığında,

$$
\left|\begin{array}{l}
\sum_{i=0}^{1} E_{i} H_{i}\left(\xi_{1}\right) \sum_{v=0}^{1} r_{v} H_{v}\left(\xi_{2}\right) \frac{I_{z}}{A} D^{(4)}+\ldots \\
-\sum_{j=0}^{3} \omega_{n, j}^{2} H_{j}\left(\xi_{1} \otimes \xi_{2}\right) I
\end{array}\right|=0,
$$

elde edilir. Denklem (23), ÇKA katsayılarının elde edilmesi amacıyla doğal frekansların temel fonksiyonu olan $H_{k}\left(\xi_{1} \otimes \xi_{2}\right)$ ile Galerkin iz düşümü yapıldığında, 


$$
\left|\sum_{i=0}^{1} \sum_{v=0}^{1} E_{i} r_{v} \frac{I_{z}}{A} e_{i v k} D^{(4)}-\omega_{n, k}^{2} e_{k}^{2} I\right|=0
$$

elde edilir. Burada, $k=0,1,2,3$,

$$
\begin{gathered}
e_{i v k}=\int_{\Omega_{1} \Omega_{2}} H_{i}\left(\xi_{1}\right) H_{v}\left(\xi_{2}\right) H_{k}\left(\xi_{1} \otimes \xi_{2}\right) \\
\rho_{1}\left(\xi_{1}\right) \rho_{2}\left(\xi_{2}\right) d \xi_{1} d \xi_{2},
\end{gathered}
$$

ve

$$
\begin{array}{r}
e_{k}^{2}=\int_{\Omega_{1} \Omega_{2}}\left[H_{k}\left(\xi_{1} \otimes \xi_{2}\right)\right]^{2} \rho_{1}\left(\xi_{1}\right) \\
\rho_{2}\left(\xi_{2}\right) d \xi_{1} d \xi_{2}
\end{array}
$$

Çubuğun doğal frekanslarının ÇKA katsayıları Denklem (24)'ün her bir $k$ değeri için çözülmesiyle elde edilir. Bunun yanında her bir doğal frekans için farklı ÇKA katsayıları elde edileceği açıktır. Her bir doğal frekans için hesaplanan ÇKA katsayıları Tablo 1'de verilmiștir.

Tablo 1'de görüldüğü gibi ÇKA ile $k=1$ ve $k=2$ için elde edilen katsayılar birbirine eşittir. Bunun yanında, doğal frekans sayısının artmasıyla birlikte beklendiği gibi daha büyük ÇKA katsayıları elde edilmiştir. Denklem (24) çözülürken, Ayrı Tekil Konvolüsyonu (ATK) ile elde edilen $D^{(4)}$ matrisinin her bir ÇKA katsayısı için yeniden hesaplanmamıştır. $\mathrm{Bu}$ durum $D^{(4)}$ matrisinin malzeme özellikleri ve belirsiz değişkenlerden bağımsız olmasindan kaynaklanmaktadır. Dolayısıyla ATK ile ÇKA yöntemlerinin bir arada kullanılması ÇKA'nın sonlu elemanlar yöntemi ile birlikte kullanılmasına göre daha avantajlıdır. Ayrıca, belirsiz doğal frekanslar için ÇKA ile matematiksel bir bağıntı elde edildiği görülmektedir.

ÇKA katsayılarının hesaplanmasının ardından, bazı doğal frekansların $(1,2,3$,
10, 20 ve 30.) olasilık yoğunluk fonksiyonu (OYF) Şekil 2'de Monte Carlo simülasyonu ile karşılaştırılmıştır.

Şekil 2'de görüldüğü gibi, ÇKA ile elde edilen çok terimli kullanılarak hesaplanan OYF ile Monte Carlo simülasyonu sonuçları birbirleri ile oldukça uyumludur. Görülen küçük farklılıklar ise, Şekil 2 elde edilirken üretilen örneklemlerin farklı olmasından kaynaklanmaktadır. Ayrıca Monte Carlo simülasyonunda 10000 örneklem üretilirken, ÇKA ile yalnızca her iki belirsiz parametreden 50'şer adet örneklem üretilmiştir. Bu sebeple ÇKA çok daha az sayıda örneklem ile doğal frekansların dağılımlarını elde etmekte kullanılabileceği görülmektedir.

\section{Tartışma ve Sonuç}

Bu çalışmada, Çokterimli Kaos Açlımı (ÇKA) bir ince çubuğunun belirsiz doğal frekanslarının bir çokterimli olarak ifade edilmesinde kullanılmıștır. Cubuğun elastisite modülü ve özgül hacmi normal dağılıma sahip belirsiz değişkenler olarak kabul edilmiş ve Hermite çok terimlileri ile ifade edilmiștir. Ayrık Tekil Konvolüsyonu (ATK) yöntemi diferansiyel denklemin çözümünde kullanılmıştır. ATK yöntemi ile ÇKA birlikte kullanıldığında her bir katsayı hesaplanırken çubuğun dördüncü dereceden türevini temsil eden karakteristik matrisin yeniden hesaplanmaması nedeniyle iyi bir avantaja sahip olduğu görülmüştür. ÇKA katsayıları ilk 30 doğal frekans için hesaplanmıștır. Bunun yanında, bazı doğal frekansların olasllık yoğunluk fonksiyonları (OYF) çizdirilmiş ve sonuçlar Monte Carlo simülasyonu ile karşılaştırılmıștır. Sonuç olarak ÇKA ile hesaplanan OYF, Monte Carlo simülasyonuna göre çok daha az sayıda örneklem kullanarak gerçekleştirildiği görülmüștür ve belirsiz doğal frekanslar, 
M. Kara vd. / İnce Bir Çubuğun Belirsiz Doğal Frekanslarının Çokterimli Kaos Açılımı ile Matematiksel Olarak Modellenmesi

belirsiz parametrelere bağlı olarak bir çokterimli olarak ifade edilmiştir.

Tablo 1. Doğal frekansların ÇKA katsayıları

\begin{tabular}{c|cccc}
\hline $\begin{array}{c}\text { Doğal } \\
\text { frekans }\end{array}$ & $\boldsymbol{\omega}_{\boldsymbol{n , 0}}[\mathbf{r} / \mathbf{s}]$ & $\boldsymbol{\omega}_{\boldsymbol{n , 1}}[\mathbf{r} / \mathbf{s}]$ & $\boldsymbol{\omega}_{\boldsymbol{n , 2}}[\mathbf{r} / \mathbf{s}]$ & $\boldsymbol{\omega}_{\boldsymbol{n , 3}}[\mathbf{r} / \mathbf{s}]$ \\
\hline 1 & $1,4325 \mathrm{E}+03$ & 320,3174 & 320,3174 & 71,6251 \\
2 & $5,7300 \mathrm{E}+03$ & $1,2813 \mathrm{E}+03$ & $1,2813 \mathrm{E}+03$ & 286,5006 \\
3 & $1,2893 \mathrm{E}+04$ & $2,8829 \mathrm{E}+03$ & $2,8829 \mathrm{E}+03$ & 644,6263 \\
4 & $2,2920 \mathrm{E}+04$ & $5,1251 \mathrm{E}+03$ & $5,1251 \mathrm{E}+03$ & $1,1460 \mathrm{E}+03$ \\
5 & $3,5813 \mathrm{E}+04$ & $8,0079 \mathrm{E}+03$ & $8,0079 \mathrm{E}+03$ & $1,7906 \mathrm{E}+03$ \\
6 & $5,1570 \mathrm{E}+04$ & $1,1531 \mathrm{E}+04$ & $1,1531 \mathrm{E}+04$ & $2,5785 \mathrm{E}+03$ \\
7 & $7,0193 \mathrm{E}+04$ & $1,5696 \mathrm{E}+04$ & $1,5696 \mathrm{E}+04$ & $3,5096 \mathrm{E}+03$ \\
8 & $9,1680 \mathrm{E}+04$ & $2,0500 \mathrm{E}+04$ & $2,0500 \mathrm{E}+04$ & $4,5840 \mathrm{E}+03$ \\
9 & $1,1603 \mathrm{E}+05$ & $2,5946 \mathrm{E}+04$ & $2,5946 \mathrm{E}+04$ & $5,8016 \mathrm{E}+03$ \\
10 & $1,4325 \mathrm{E}+05$ & $3,2032 \mathrm{E}+04$ & $3,2032 \mathrm{E}+04$ & $7,1625 \mathrm{E}+03$ \\
11 & $1,7333 \mathrm{E}+05$ & $3,8758 \mathrm{E}+04$ & $3,8758 \mathrm{E}+04$ & $8,6666 \mathrm{E}+03$ \\
12 & $2,0628 \mathrm{E}+05$ & $4,6126 \mathrm{E}+04$ & $4,6126 \mathrm{E}+04$ & $1,0314 \mathrm{E}+04$ \\
13 & $2,4209 \mathrm{E}+05$ & $5,4134 \mathrm{E}+04$ & $5,4134 \mathrm{E}+04$ & $1,2105 \mathrm{E}+04$ \\
14 & $2,8077 \mathrm{E}+05$ & $6,2782 \mathrm{E}+04$ & $6,2782 \mathrm{E}+04$ & $1,4039 \mathrm{E}+04$ \\
15 & $3,2231 \mathrm{E}+05$ & $7,2071 \mathrm{E}+04$ & $7,2071 \mathrm{E}+04$ & $1,6116 \mathrm{E}+04$ \\
16 & $3,6672 \mathrm{E}+05$ & $8,2001 \mathrm{E}+04$ & $8,2001 \mathrm{E}+04$ & $1,8336 \mathrm{E}+04$ \\
17 & $4,1399 \mathrm{E}+05$ & $9,2572 \mathrm{E}+04$ & $9,2572 \mathrm{E}+04$ & $2,0700 \mathrm{E}+04$ \\
18 & $4,6413 \mathrm{E}+05$ & $1,0378 \mathrm{E}+05$ & $1,0378 \mathrm{E}+05$ & $2,3207 \mathrm{E}+04$ \\
19 & $5,1713 \mathrm{E}+05$ & $1,1563 \mathrm{E}+05$ & $1,1563 \mathrm{E}+05$ & $2,5857 \mathrm{E}+04$ \\
20 & $5,7300 \mathrm{E}+05$ & $1,2813 \mathrm{E}+05$ & $1,2813 \mathrm{E}+05$ & $2,8650 \mathrm{E}+04$ \\
21 & $6,3173 \mathrm{E}+05$ & $1,4126 \mathrm{E}+05$ & $1,4126 \mathrm{E}+05$ & $3,1587 \mathrm{E}+04$ \\
22 & $6,9333 \mathrm{E}+05$ & $1,5503 \mathrm{E}+05$ & $1,5503 \mathrm{E}+05$ & $3,4667 \mathrm{E}+04$ \\
23 & $7,5779 \mathrm{E}+05$ & $1,6945 \mathrm{E}+05$ & $1,6945 \mathrm{E}+05$ & $3,7890 \mathrm{E}+04$ \\
24 & $8,2512 \mathrm{E}+05$ & $1,8450 \mathrm{E}+05$ & $1,8450 \mathrm{E}+05$ & $4,1256 \mathrm{E}+04$ \\
25 & $8,9531 \mathrm{E}+05$ & $2,0020 \mathrm{E}+05$ & $2,0020 \mathrm{E}+05$ & $4,4766 \mathrm{E}+04$ \\
26 & $9,6837 \mathrm{E}+05$ & $2,1653 \mathrm{E}+05$ & $2,1653 \mathrm{E}+05$ & $4,8419 \mathrm{E}+04$ \\
27 & $1,0443 \mathrm{E}+06$ & $2,3351 \mathrm{E}+05$ & $2,3351 \mathrm{E}+05$ & $5,2215 \mathrm{E}+04$ \\
28 & $1,1231 \mathrm{E}+06$ & $2,5113 \mathrm{E}+05$ & $2,5113 \mathrm{E}+05$ & $5,6154 \mathrm{E}+04$ \\
29 & $1,2048 \mathrm{E}+06$ & $2,6939 \mathrm{E}+05$ & $2,6939 \mathrm{E}+05$ & $6,0238 \mathrm{E}+04$ \\
30 & $1,2894 \mathrm{E}+06$ & $2,8832 \mathrm{E}+05$ & $2,8832 \mathrm{E}+05$ & $6,4469 \mathrm{E}+04$ \\
\hline & & & & \\
\hline
\end{tabular}



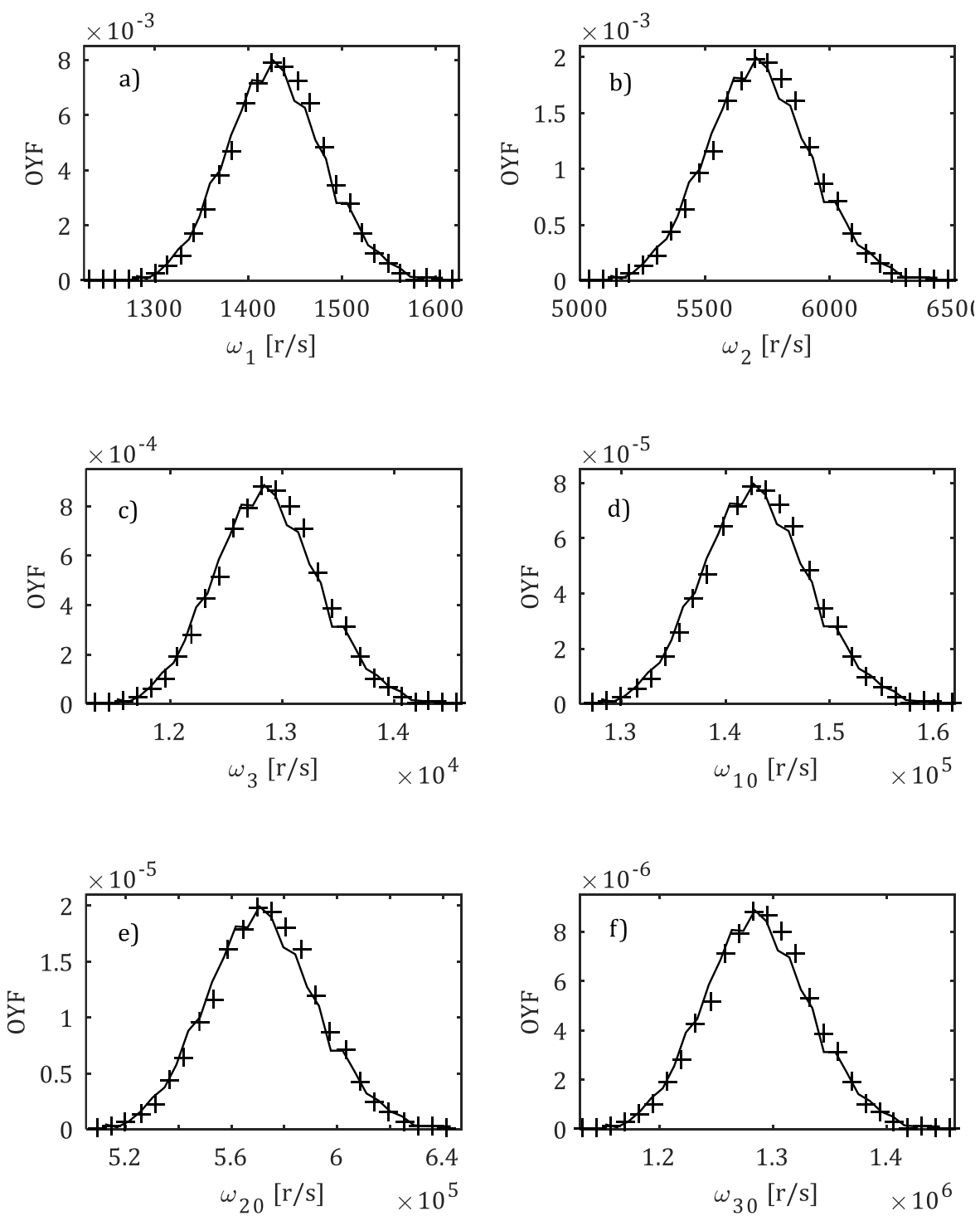

Sekil 2. Doğal frekansların olasılık yoğunluk fonksiyonları a) 1. doğal frekans, b) 2. doğal frekans, c) 3. doğal frekans, d) 10. doğal frekans, e) 20. doğal frekans, f) 30. doğal frekans (çizgi: ÇKA, +: Monte Carlo simülasyonu)

\section{Kaynakça}

[1] Elishakoff, I., Haftka, R.T., Fang, J. 1994. Structural design under bounded uncertainty-Optimization with anti-optimization, Computers \& Structures, Cilt. 53, s. 1401-5. doi:10.1016/0045-7949(94)904057.
[2] Moore, R.E. 1979. Methods and applications of interval analysis. 2nd, Siam.

[3] Hanss, M. 2013. Fuzzy Arithmetic for Uncertainty Analysis. Springer, Berlin, Heidelberg, s. 235-40.

[4] Kumar, V., Schuhmacher, M. 2005. Fuzzy uncertainty analysis in system modelling, Computer Aided Chemical Engineering, Cilt. 20, s. 
M. Kara vd. / İnce Bir Çubuğun Belirsiz Doğal Frekanslarının Çokterimli Kaos Açılımı ile Matematiksel Olarak Modellenmesi

391-6. doi:10.1016/S1570- Computer Methods in Applied 7946(05)80187-7.

Mechanics and Engineering,

[5] Evans, M., Swartz, T. 2000. Approximating Integrals via Monte Carlo and Deterministic Methods. OUP, Oxford.

[6] Rubinstein, R.Y., Kroese, D.P. 2016. Simulation and the Monte Carlo Method. John Wiley \& Sons.

[7] Lyon, R., DeJong, R. 1995. Statistical Energy Analysis of Dynamics Systems: Theory and Applications. 2nd, MIT Press.

[8] Ghanem, R.G., Spanos, P.D. 2003. Stochastic Finite Elements: A Spectral Approach. Courier Corporation.

[9] Sepahvand, K., Marburg, S., Hardtke, H-J. 2007. Numerical solution of one-dimensional wave equation with stochastic parameters using generalized polynomial chaos expansion, Journal of Computational Acoustics, Cilt. 15, s.579-93. doi:10.1142/S0218396X07003524.

[10] Sepahvand, K., Marburg, S., Hardtke, H-J. 2010. Uncertainty quantification in stochastic systems using polynomial chaos expansion, International Journal of Applied Mechanics, Cilt. 2, s. 305-53. doi:10.1142/S1758825110000524.

[11] Wei, G.W. 1999. Discrete singular convolution for the solution of the Fokker-Planck equation, The Journal of Chemical Physics, Cilt. 110, s.8930-42. doi:10.1063/1.478812.

[12] Wei, G.W. 2000. Solving quantum eigenvalue problems by discrete singular convolution, Journal of Physics B: Atomic, Molecular and Optical Physics, Cilt.33, s.343-52. doi:10.1088/0953-4075/33/3/304.

[13] Wei, G.W. 2001. A new algorithm for solving some mechanical problems,

$$
\begin{aligned}
& \text { doi:10.1016/S0045- } \\
& \text { 7825(00)00219-X. }
\end{aligned}
$$

[14] Wei, G.W. 2001. Discrete singular convolution for beam analysis, Engineering Structures, Cilt. 23, s. 1045-53. doi:10.1016/S01410296(01)00016-5.

[15] Wei, G.W. 2001. Vibration analysis by discrete singular convolution, Journal of Sound and Vibration, Cilt. 244, s. 535-53. doi:10.1006/jsvi.2000.3507.

[16] Seçgin, A., Sarıgül, A.S. 2009. A novel scheme for the discrete prediction of high-frequency vibration response: Discrete singular convolution-mode superposition approach, Journal of Sound and Vibration, Cilt. 320, s. 1004-22. doi:10.1016/j.jsv.2008.08.031.

[17] Seçgin, A., Sarıgül, A.S. 2008. Free vibration analysis of symmetrically laminated thin composite plates by using discrete singular convolution (DSC) approach: Algorithm and verification, Journal of Sound and Vibration, Cilt. 315, s. 197-211. doi:10.1016/j.jsv.2008.01.061.

[18] Rao, S.S. 2011. Mechanical vibrations. Prentice Hall.

[19] Wei, G.W, Zhao, Y.B., Xiang, Y. 2002, Discrete singular convolution and its application to the analysis of plates with internal supports, Part 1: Theory and algorithm, International Journal for Numerical Methods in Engineering, Cilt. 55, s. 913-46. doi:10.1002/nme.526.

[20] Wang, X, Xu, S. 2010. Free vibration analysis of beams and rectangular plates with free edges by the discrete singular convolution, Journal of Sound and Vibration, Cilt. 
M. Kara vd. / İnce Bir Çubuğun Belirsiz Doğal Frekanslarının Çokterimli Kaos Açılımı ile Matematiksel Olarak Modellenmesi
329,
s. $\quad 1780-92$

doi:10.1016/j.jsv.2009.12.006.

[21] Zhao, S., Wei, G.W., Xiang, Y. 2005.

DSC analysis of free-edged beams by an iteratively matched boundary method, Journal of Sound and Vibration, Cilt. 284, s. 487-93. doi:10.1016/j.jsv.2004.08.037. 